\title{
Influência do Condicionamento Ambiental na Resistência à Tração de Compósitos de Carbono/Epóxi Reparados
}

\author{
Sérgio Mayer \\ EMBRAER \\ Departamento de Engenharia Mecânica e Aeronáutica, ITA \\ Geraldo M. Cândido \\ Divisão de Homologação, IFI, CTA \\ Mirabel C. Rezende \\ Divisão de Materiais, IAE, CTA
}

\begin{abstract}
Resumo: Com o contínuo crescimento do uso de compósitos poliméricos estruturais na produção industrial de peças aeronáuticas, torna-se imperativo desenvolver técnicas de reparos de danos aplicáveis aos diversos tipos de laminados. O procedimento normalmente utilizado para definir o reparo de compósitos laminados, envolve a simulação do dano em corpos-de-prova representativos dos componentes. Este trabalho apresenta a técnica de reparo estrutural, tipo chanfro, de laminados de carbono/epóxi de aplicação aeronáutica, pelo uso do tecido de carbono/epóxi. Os laminados de carbono/epóxi, sem e com reparos, foram submetidos ao condicionamento ambiental em duas condições diferentes (ambiente: $23 \pm 5{ }^{\circ} \mathrm{C}$ e $50 \pm 5 \%$ de umidade relativa e úmida: $65 \pm 5{ }^{\circ} \mathrm{C}$ e $95 \pm 5 \%$ de umidade relativa), e os reparos foram realizados com quatro diferentes sobreposições das camadas de tecido de carbono $(9,0 ; 12,7 ; 15,0$ e 20,0 mm). Todas as famílias de reparo foram submetidas ao carregamento em tração em temperaturas ambiente e elevada $\left(82{ }^{\circ} \mathrm{C}\right)$. Os melhores resultados da propriedade mecânica dos laminados reparados foram obtidos com as sobreposições de 15,0 e 20,0 mm, recompondo a resistência em 80,7 e $84,0 \%$, respectivamente, em relação ao laminado sem reparo. O condicionamento com umidade e temperatura elevadas diminuiu a resistência em tração em até $90 \%$ dos laminados reparados, favorecendo a falha por descolamento entre o laminado base e o reparo (falha no adesivo).
\end{abstract}

Palavras-chave: Compósitos poliméricos, reparo, laminados, danos.

\section{Influence of the Hygrothermal Conditioning on the Tensile Strength of Repaired Carbon/Epoxy Composites}

Abstract: The increasing use of structural polymer composites in the aeronautical industry has required the development of repairing techniques of damages found in different types of laminates. The most popular procedure to investigate the repairing of laminate composite has been to repair simulated damages in laminated composite specimens. This work shows the structural repair technique, of scarf type, of a typical carbon/epoxy laminate used in the aeronautical industry, using carbon/epoxy fabric. The carbon/epoxy laminates, with and without repairs, were subjected to two hygrothermal conditions (ambient: $23 \pm 5{ }^{\circ} \mathrm{C}$ and $50 \pm 5 \%$ of relative humidity, and wet: $65 \pm 5{ }^{\circ} \mathrm{C}$ and $95 \pm 5 \%$ of relative humidity). The repairs were made by using four different overlaps of the carbon fabric plies $(9.0 ; 12.7 ; 15.0$ and $20.0 \mathrm{~mm})$. All repaired families were subjected to tensile tests performed at room and elevated $\left(82{ }^{\circ} \mathrm{C}\right)$ temperatures. The highest tensile strength values were obtained with laminates repaired by the 15.0 and $20.0 \mathrm{~mm}$ overlaps, recovering 80.7 and $84.0 \%$ of the strength respectively, in relation to the laminate without repair. The conditioning under elevated humidity and temperature decreased the tensile strength up to $90 \%$ of the repaired laminates, favoring the adhesive failure by debonding between the base laminate and the repair.

Keywords: Polymer composites, repair, laminates, damages.

\section{Introdução}

Desde que os compósitos poliméricos avançados passaram a ser utilizados na fabricação de peças aeronáuticas, a questão de reparos estruturais tem recebido considerável atenção, tanto do ponto de vista econômico como de engenharia. Quando estruturas aeronáuticas são projetadas e fabricadas com materiais pré-impregnados muitas considerações estão envolvidas, dentre elas as exigências estruturais. Componentes classificados como níveis I e II nas aplicações aeronáuticas (alto comprometimento estrutural e de uso estrutural, respectivamente), quando danificados 
durante as etapas de fabricação, manuseio, transporte, montagem de subconjuntos ou em serviço, devem ser submetidos a um estudo analítico. A análise sobre a necessidade ou conveniência do reparo deve ser fundamentada em dados, como a localização, profundidade e tamanho do dano, probabilidade de sucesso e testes que assegurem a adequada execução do reparo ${ }^{[1]}$. Caso a execução do reparo seja viável, esse é realizado com um procedimento pré-determinado, que visa recompor estruturalmente o laminado.

Na execução de um reparo estrutural, o material da região danificada é removido e substituído por um novo, essencialmente compatível, reproduzindo de forma escalonada a mesma seqüência de empilhamento de camadas, definida no projeto original do componente. Após a cura da resina do préimpregnado utilizado no reparo, o laminado reparado deve apresentar características mecânicas as mais próximas possíveis daquelas do projeto original. Com isso, é de se esperar que a relação original resistência/rigidez seja restaurada e garantida sob vários tipos de esforço mecânico, tais como tração, cisalhamento e fadiga, sob diferentes condicionamentos ambientais, semelhante à relação prevista para o componente sem danos ${ }^{[1,2]}$. Em sendo assim, o reparo estrutural tem como função atuar como um meio que assegure a transferência de esforços entre as extremidades da área afetada (transferência de esforços através do material de reparo).

Os danos em um compósito polimérico podem ser originados por vazamentos na bolsa de vácuo (quedas de pressão), vazamento de resina e contração do molde durante a cura, a presença de objeto estranho no interior do laminado, usinagem inadequada, tensões de borda livre, seqüência de empilhamento de camadas imprópria, desalinhamento na orientação das fibras, impacto de raio, granizo e pássaros, manuseio inadequado da peça, erosão do compósito, entre outros fatore ${ }^{[3-6]}$. Esses problemas podem afetar a integridade do compósito, causando trincas, delaminações, empenamentos, rugas, vazios e quebra das fibras, degradando as propriedades estruturais de resistência e rigidez do laminado. Para isso, faz-se necessário determinar a área e a profundidade do dano considerando-se, também, a ocorrência de delaminação em volta da área danificada e a presença de material estranho como sujeira, poeira e umidade ${ }^{[7,8]}$. Alguns desses defeitos são facilmente localizados e detectados visualmente na inspeção da qualidade do produto, enquanto outros, localizados no interior do compósito, só são detectados com o auxílio de técnicas de inspeção não destrutiva, como ultra-som ou difração de raios- $\mathrm{X}^{[9]}$.

O objetivo do presente trabalho é mostrar a influência do condicionamento ambiental em laminados base de préimpregnado de tecido de carbono/epóxi com orientação $\left(0^{\circ}, 90^{\circ}\right)$, reparados com diferentes comprimentos de sobreposição de tecido de carbono/epóxi. A influência dos parâmetros estudados foi avaliada por meio de ensaios de resistência à tração e microscopia óptica.

\section{Materiais e Métodos}

Os laminados base foram processados com pré-impregnado de carbono/epóxi da Hexcel Composites, na forma de tecido bidirecional estilo eight-harness satin weave (8-HS), atendendo aos requisitos de projeto e fabricação de peças estruturais para aplicações aeronáuticas ${ }^{[10]}$. A fibra de carbono do tecido é de alta resistência, tratada para maior compatibilidade química com a matriz epóxi F-584. O tecido de carbono utilizado no reparo é impregnado com a resina epóxi F-155, também da empresa Hexcel Composites. Estes sistemas de matriz já contêm o endurecedor parcialmente curado, ou seja, no estágio $\mathrm{B}^{[11,12]}$.

O processamento dos laminados base consistiu no empilhamento de seis camadas de pré-impregnados de carbono/epóxi F-584 $\left(0^{\circ}, 90^{\circ}\right)$ e cura em autoclave. O ciclo completo de cura ocorreu a $177^{\circ} \mathrm{C}$ com $0,69 \mathrm{MPa}$ de pressão e vácuo de 0,083 $\mathrm{MPa}$ em bolsa de vácuo (Figura 1). Após a cura, o compósito foi desmoldado e inspecionado por ultrasom pela técnica de transmissão por coluna de água com transdutor de $5 \mathrm{MHz}$ e jatos de $3 \mathrm{~mm}$ de diâmetro. Nesta etapa não foi detectada a existência de defeitos de fabricação, tais como trincas, porosidades, delaminações e outros defeitos que pudessem comprometer a estrutura do laminado base. Em seguida, foi iniciada a preparação dos corpos-deprova e a simulação de danos nos laminados dos corpos-deprova reparados.

\section{Procedimento de reparo}

Para a simulação do dano foi feita a usinagem de um rasgo transversal de $12,7 \mathrm{~mm}$ de largura no laminado base, conforme mostra a Figura 2. Dependendo da extensão da sobreposição de camadas a ser utilizada no reparo, foi realizado um chanfro de dimensões $L$ por meio de lixamento com uma lixadeira manual, simulando a execução de um reparo em campo.

Após a introdução do chanfro, os laminados base foram submetidos ao condicionamento ambiental em câmara úmida à temperatura de $65{ }^{\circ} \mathrm{C}, 95 \%$ de umidade relativa por 45 dias. Esse procedimento foi realizado de modo a simular um caso real de exposição de um laminado danificado. Após este condicionamento, os laminados base foram secos em estufa a $121{ }^{\circ} \mathrm{C}$ por $1 \mathrm{~h}$, sob vácuo de $0,078 \mathrm{MPa}$, no mínimo. Após a secagem dos laminados, a superfície da região do chanfro foi levemente lixada com uma lixa grana 180, sendo em seguida limpa com um pano embebido em álcool isopropílico. Após a limpeza foi realizado o teste de quebra d'água para verificar a eficiência desse procedimento ${ }^{[4]}$. Em caso de não

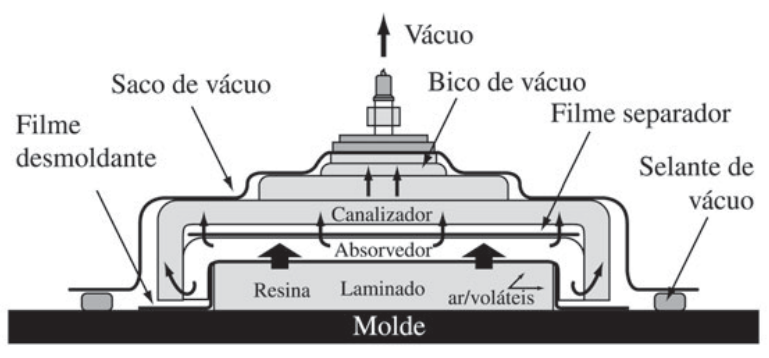

Figura 1. Esquema da preparação do saco de vácuo ${ }^{[9]}$. 


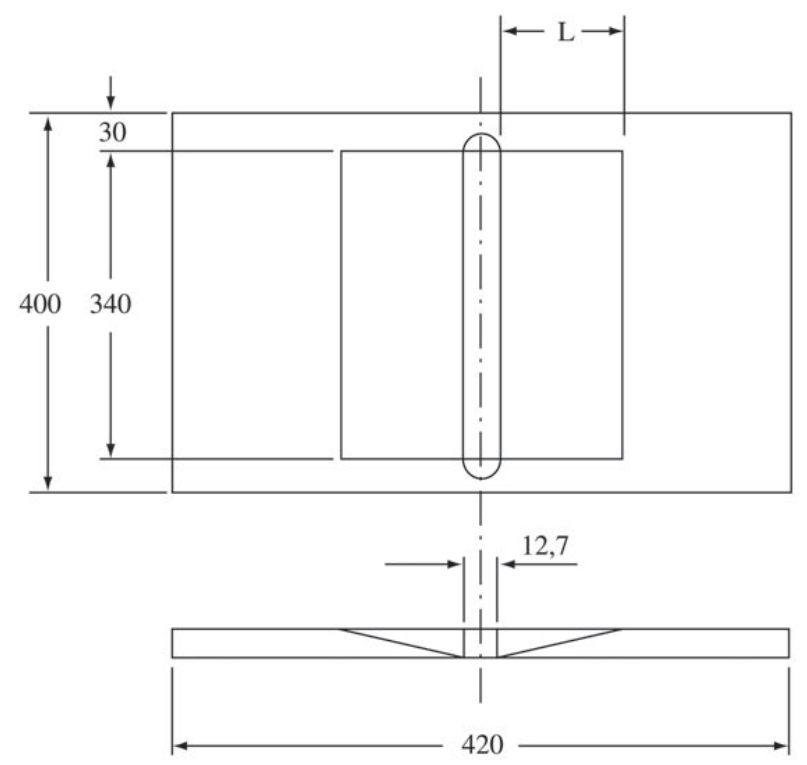

Figura 2. Dimensão $L$ do chanfro (mm) produzido nos laminados base.

atender aos requisitos, ou seja, não formar um filme contínuo de água, o procedimento de limpeza foi novamente realizado. O teste de quebra d'água é executado molhando-se toda a superfície da área a ser reparada com água destilada e deionizada, observando se um filme contínuo de água é formado por um período mínimo de $30 \mathrm{~s}$, sem que ocorra a quebra desse filme de água na superfície ${ }^{[9]}$. Após esse teste, os laminados foram secos em estufa por $30 \mathrm{~min}$ a $60^{\circ} \mathrm{C}$ e o reparo foi executado.

A Figura 3 ilustra o esquema utilizado na realização do reparo, mostrando as camadas de tecido de carbono $\left(A_{1}-A_{8}\right)$ utilizadas no reparo do laminado base, com um sistema de resina epóxi de cura a $121^{\circ} \mathrm{C}$; a região de sobreposição $G$ e o filme adesivo utilizado $\left(A_{F}\right)$. A metodologia utilizada na execução dos reparos é descrita a seguir ${ }^{[9,13]}$ :

1. Aplicação de filme adesivo FM-73 $\left(A_{F}\right)$ de $0,415 \mathrm{~kg} / \mathrm{m}^{2}$, fornecido pela Cytec, em toda a superfície do reparo (Figura 3).

2. Laminação das oito camadas do material de reparo $\left(0^{\circ}\right.$; $90^{\circ}$ ), respeitando a sobreposição $G$ de 9,$0 ; 12,7 ; 15,0$ e 20,0 $\mathrm{mm}$ para cada laminado base, respectivamente, e a quantidade total de 8 camadas.

3. Preparação do laminado reparado para a cura, montando um novo saco de vácuo (Figura 1).

4. Cura em estufa do pré-impregnado utilizado no reparo, atendendo aos procedimentos descritos a seguir:

4.1 Aplicação de vácuo mínimo de 0,078 MPa. Aquecimento até a temperatura de $121 \pm 5^{\circ} \mathrm{C}$, à razão de aquecimento de 0,5 a $2,7^{\circ} \mathrm{C} / \mathrm{min}$. Manutenção a esta temperatura por um período mínimo de 120 min sob vácuo. Resfriamento até $65^{\circ} \mathrm{C}$ sob vácuo, à razão de $2,7^{\circ} \mathrm{C} / \mathrm{min}$, no máximo.

4.2. Remoção de todo o material utilizado na preparação do saco de vácuo dos laminados reparados.
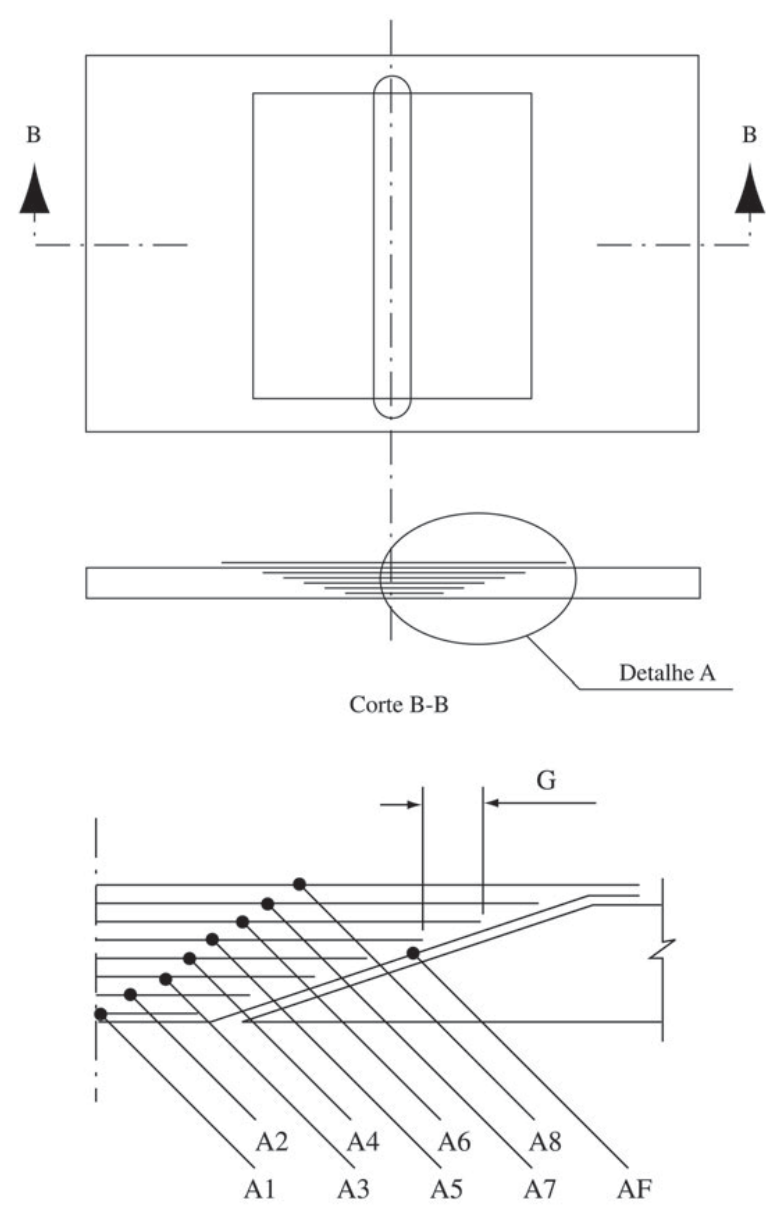

Detalhe A

Figura 3. Esquema da laminação das camadas do reparo de $A_{1}-A_{8}$, onde $G$ é a região de sobreposição.

\section{Condicionamento ambiental}

O condicionamento ambiental dos corpos-de-prova (cdp) foi realizado atendendo duas condições distintas. A primeira foi manter os corpos-de-prova na condição ambiente normal do laboratório $\left(23 \pm 5{ }^{\circ} \mathrm{C}, 50 \pm 5 \%\right.$ de umidade relativa), denominada de "seca ambiente". A segunda foi conduzida a $65 \pm 5{ }^{\circ} \mathrm{C}$ com teor de umidade relativa de $95 \pm 5 \%$ em uma câmara de climatização, condição esta denominada neste trabalho de "úmida". Semanalmente, os corpos-de-prova foram removidos da câmara por pequenos intervalos de tempo para fazer a determinação do ganho de massa em uma balança analítica, com precisão de $0,1 \mathrm{mg}$. O efeito desta remoção sobre a determinação do ganho de massa foi desprezado. Este procedimento se repetiu até que o limite efetivo de saturação de umidade fosse alcançado ${ }^{[14,15]}$.

\section{Preparação dos Corpos-de-Prova para o Ensaio de Tração}

A geometria do corpo-de-prova utilizado no ensaio de tração apresentou as dimensões nominais de $25,4 \times 420 \mathrm{~mm}$ e 
tabs de $60 \mathrm{~mm}$ de comprimento (fabricado com material préimpregnado de tecido bidirecional de fibra de vidro estilo 7781 e matriz epóxi F155 de cura a $121^{\circ} \mathrm{C}$, da Hexcel Composites), colados com o adesivo EA934NA, do fabricante Loctite, de cura a $65^{\circ} \mathrm{C}$ por $1 \mathrm{~h}$ (Figura 4 ). Em seguida, um total de 120 corpos-de-prova foram cortados, sendo 24 sem danos e 96 com a introdução de danos (chanfro) e reparados. Este material foi dividido em dois lotes, submetido aos dois tipos de condicionamento, à temperatura ambiente e úmido.

\section{Ensaio de Resistência à Tração}

Após os corpos-de-prova terem atingido a saturação de umidade foram divididos em três lotes, o primeiro relativo ao condicionamento à temperatura ambiente, denominado de "seco ambiente", o segundo e o terceiro lotes referem-se aos corpos-de-prova submetidos ao condicionamento úmido, sendo um mantido à temperatura ambiente por $24 \mathrm{~h}$ antes do ensaio de tração, chamado de "úmido ambiente" e o terceiro ensaiado a $82^{\circ} \mathrm{C}$, logo após a retirada da câmara de climatização, denominado de "úmido elevado". Os ensaios de tração atenderam aos procedimentos da norma ASTM-
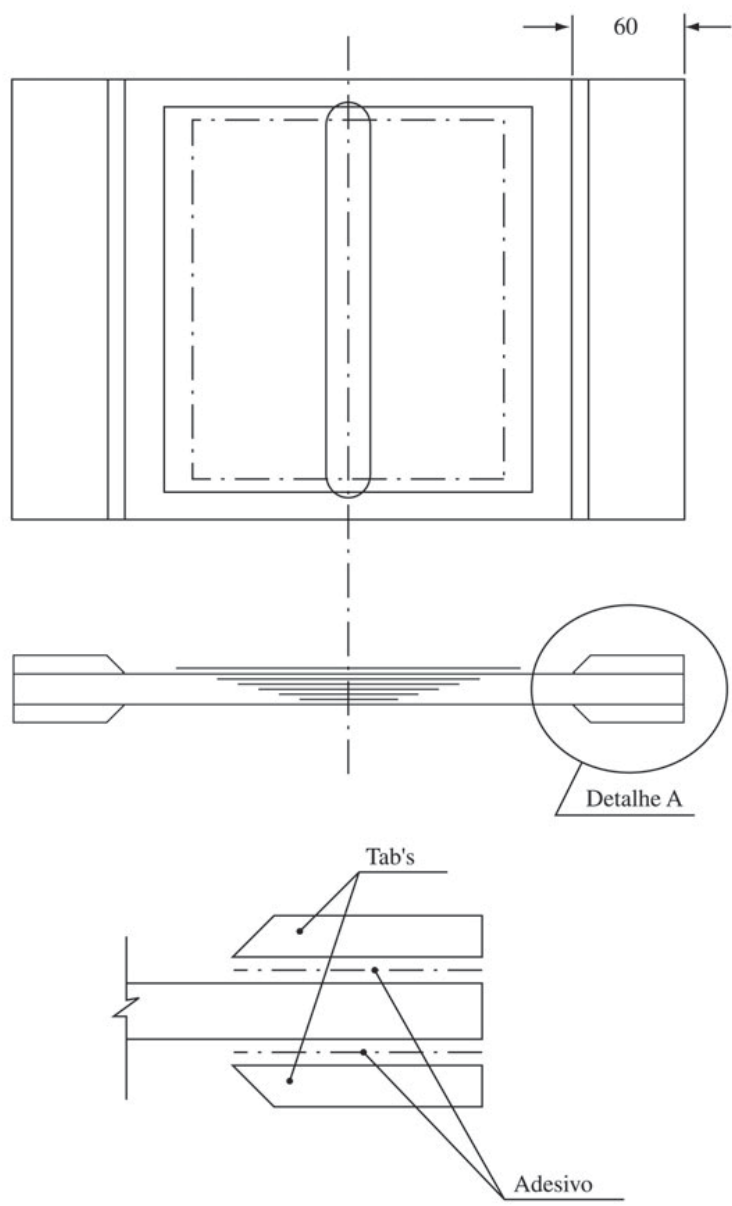

Detalhe A

Figura 4. Colagem dos tabs.
D-3039 ${ }^{[16]}$, às temperaturas ambiente $\left(23 \pm 5^{\circ} \mathrm{C}\right)$ e elevada $\left(82 \pm 5^{\circ} \mathrm{C}\right)$. Os ensaios do lote úmido elevado visam atender aos requisitos aplicáveis a componentes aeronáuticos em serviço. O MIL-HDBK-17 ${ }^{[17]}$ descreve os procedimentos de ensaios para compósitos poliméricos ${ }^{[10]}$.

\section{Resultados e Discussão}

Os resultados obtidos nos ensaios de tração dos laminados de carbono/epóxi reparados com pré-impregnados de carbono/epóxi são apresentados na Tabela 1 e na Figura 5, mostrando as médias das cargas de ruptura e as regiões onde ocorrerem as falhas. A análise dos resultados é apresentada utilizando-se os valores de carga de ruptura, pelo fato da variação da espessura dos corpos-de-prova reparados e o modo de falha inviabilizarem o cálculo de resistência à tração. Tal procedimento já é adotado por outros autores na literatura ${ }^{[2]}$.

A análise da Figura 5 e da Tabela 1 mostrou que a carga de ruptura dos laminados base, na condição seca ambiente, diminuiu após a realização dos reparos, sendo este decréscimo mais acentuado com a redução da região de sobreposição do tecido de carbono utilizado no reparo, ou seja, os corpos-deprova com sobreposição de $9,0 \mathrm{~mm}$ apresentaram a maior queda nos valores de resistência à tração (37\%); já a família com maior sobreposição (20,0 mm) apresentou o menor decréscimo desta propriedade (16\%), em relação aos corpos-de-prova sem reparo.

A análise dos corpos-de-prova sem reparo ensaiados mostrou que estes falharam no próprio laminado base (Tabela 1), como esperado. No entanto, as famílias com reparos de sobreposição de 9,0;12,7 e 15,0 mm, com condicionamento seco ambiente, romperam na região de reparo, enquanto a sobreposição de $20,0 \mathrm{~mm}$ rompeu no laminado base (Figura 6), mostrando em todos os casos um modo de falha tipo translaminar ${ }^{[3]}$. A maior porcentagem de desvio nos resultados desta família é observada para a sobreposição de 9,0 $\mathrm{mm}(11,3 \%)$ e as menores para as famílias de laminados sem reparo e com sobreposição de $20,0 \mathrm{~mm} \mathrm{(3,1}$ e $2,1 \%$, respectivamente).

A família com sobreposição de $9,0 \mathrm{~mm}$, submetida ao condicionamento úmido e exposta por $24 \mathrm{~h}$ ao condicionamento ambiente, apresenta ruptura nas regiões do reparo e do adesivo (Figura 7), indicando que o material de reparo utilizado mostrou-se susceptível à presença de umidade e que sobreposições iguais ou menores que 9,0 mm não são viáveis de serem utilizadas, apresentando-se como áreas insuficientes para a transferência de esforços. Já as famílias com maior dimensão da sobreposição, submetidas ao condicionamento úmido ambiente falharam no reparo (fratura translaminar). Apesar dos laminados base ensaiados na condição úmido ambiente apresentarem uma maior queda nos valores de resistência à tração, em relação aos ensaiados no condicionamento seco ambiente, os desvios padrão dos resultados das duas famílias avaliadas não apresentam diferenças significativas. Esta pequena variação nos valores de desvio determinados e a recuperação de parte de sua resistência à tração indicam que o processo de absorção e 
Tabela 1. Resistência à tração dos laminados base, sem e com reparos de diferentes sobreposições, submetidos aos diferentes condicionamentos ambientais.

\begin{tabular}{|c|c|c|c|c|}
\hline $\begin{array}{l}\text { Condicionamento } \\
\text { do laminado base }\end{array}$ & Sobreposição (mm) & Carga média* $(\mathbf{N})$ & Desvio (\%) & Local de falha \\
\hline \multirow{5}{*}{ Seco ambiente } & Sem reparo & 54375 & 3,1 & Laminado base \\
\hline & 9,0 & 34406 & 11,3 & Reparo \\
\hline & 12,7 & 42125 & 9,8 & Reparo \\
\hline & 15,0 & 43875 & 7,8 & Reparo \\
\hline & 20,0 & 45688 & 2,1 & Laminado base \\
\hline \multirow{5}{*}{ Úmido ambiente } & Sem reparo & 54375 & 2,7 & Laminado base \\
\hline & 9,0 & 34344 & 3,8 & Reparo/Adesivo \\
\hline & 12,7 & 37313 & 8,4 & Reparo \\
\hline & 15,0 & 40938 & 7,7 & Reparo \\
\hline & 20,0 & 41188 & 5,9 & Reparo \\
\hline \multirow{5}{*}{ Úmido elevado } & Sem reparo & 54300 & 5,2 & Laminado base \\
\hline & 9,0 & - & - & - \\
\hline & 12,7 & 5455 & 3,7 & Adesivo \\
\hline & 15,0 & 5381 & 2,9 & Adesivo \\
\hline & 20,0 & 8372 & 5,4 & Adesivo \\
\hline
\end{tabular}

* média referente a 08 determinações.

Tecido de carbono reparado com tecido de carbono

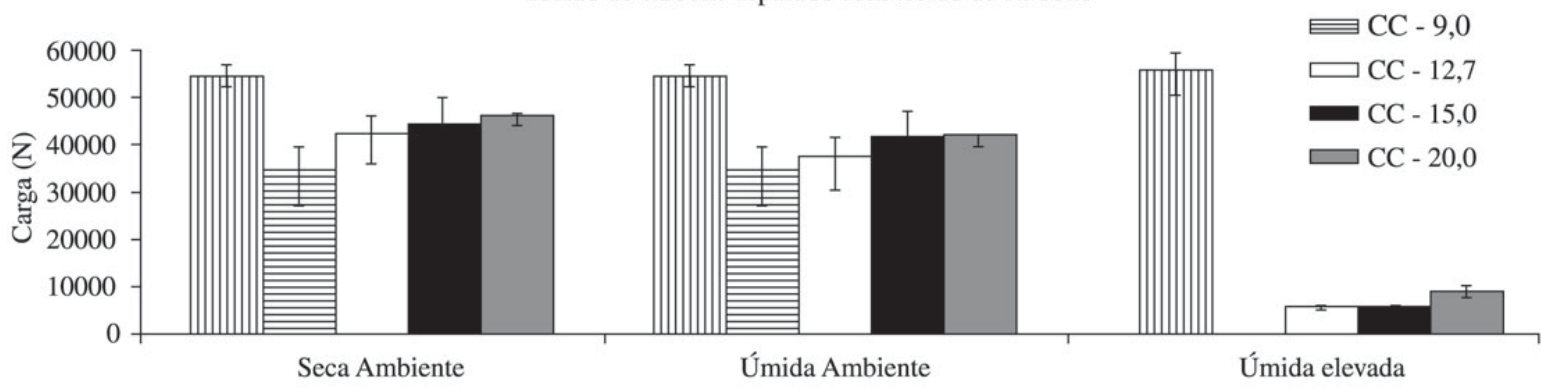

Figura 5. Carga de ruptura média dos corpos-de-prova de carbono/epóxi, sem e com reparo de tecido de carbono/epóxi, sob diferentes condicionamentos ambientais (CC: sobreposição da região do reparo).

dessorção de água neste caso é reversível.

Os corpos-de-prova das famílias com reparos de sobreposição de 12,$7 ; 15,0$ e $20,0 \mathrm{~mm}$, com condicionamento úmido elevado, romperam na região do adesivo, indicando que este material é susceptível à presença de umidade à temperatura elevada. A combinação destes parâmetros acelera, provavelmente, a degradação do adesivo e/ou a queda da temperatura de transição vítrea da resina utilizada no adesivo, prejudicando, conseqüentemente, a interface formada entre o laminado base e o material do reparo. Na condição úmida elevada observou-se uma redução mais acentuada nos valores médios de carga de ruptura, da ordem de $90 \%$, para as sobreposições de 12,7 e $15,0 \mathrm{~mm}$ e cerca de $85 \%$ para sobreposição de $20,0 \mathrm{~mm}$, sendo que a falha ocorreu na área de colagem, demonstrando que o filme adesivo é susceptível à umidade. Os valores de desvio padrão apresentaram uma variação entre 5,4 (20,0 $\mathrm{mm}$ de sobreposição) e $2,9 \%(15,0 \mathrm{~mm}$ de sobreposição). Esta menor variação dos resultados em torno da média deve-se ao rompimento dos corpos-de-prova na região do adesivo. Pelo fato das famílias com sobreposição de 12,7 e 15,0 mm já terem apresentado falha na região do adesivo, tornou-se desnecessária a avaliação dos corpos-de-prova com sobreposição de 9,0 mm. Estes resultados sugerem que novos filmes adesivos e materiais utilizados no reparo, mais resistentes à umidade, devam ser avaliados na execução de reparos de laminados de carbono/epóxi com tecido de carbono/epóxi.

Comparando-se os corpos-de-prova sem reparo, ensaiados nas condições seco ambiente, úmido ambiente e úmido elevado, não se observou uma variação em seus valores médios de carga de ruptura. No entanto, comparando-se as famílias com corpos-de-prova reparados, ensaiadas nas condições seco e úmido ambiente, verificou-se a ocorrência de um decréscimo contínuo da resistência à tração, mostrando o efeito deletério da umidade nas estruturas reparadas, como mencionado na literatura ${ }^{[18]}$.

\section{Conclusões}

Analisando-se os resultados pode-se concluir que à temperatura ambiente, a umidade apresenta pouca influência na 


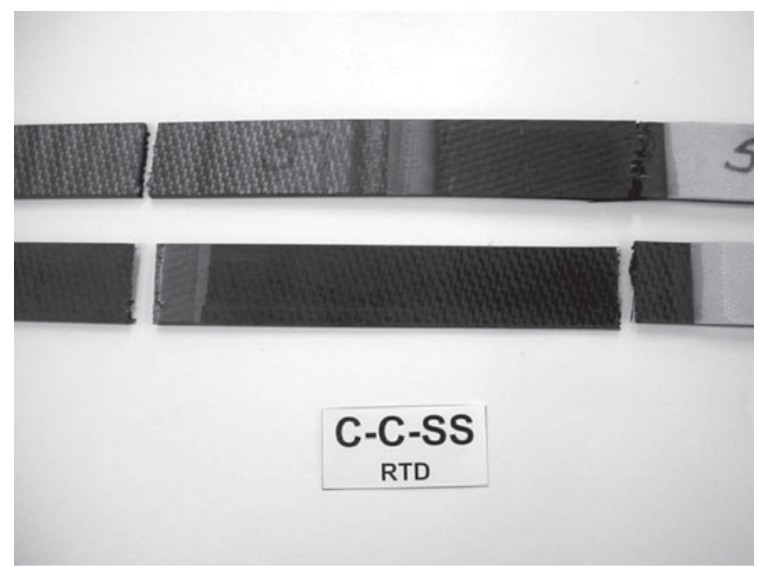

a)

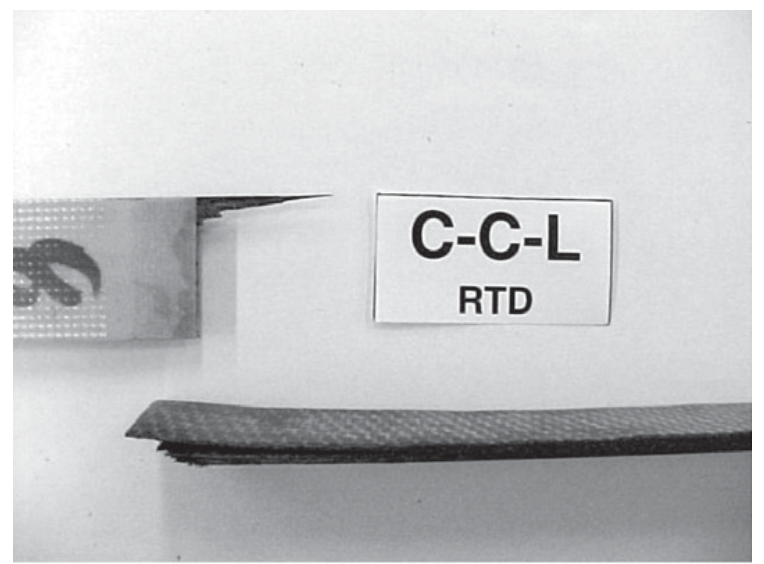

b)

Figura 6. Falha típica dos laminados base com reparo, sob condicionamento seco ambiente. a) falha no reparo (sobreposições de 9,0; 12,7; e 15,0 mm); b) falha no laminado base (sobreposição de $20,0 \mathrm{~mm}$ ).

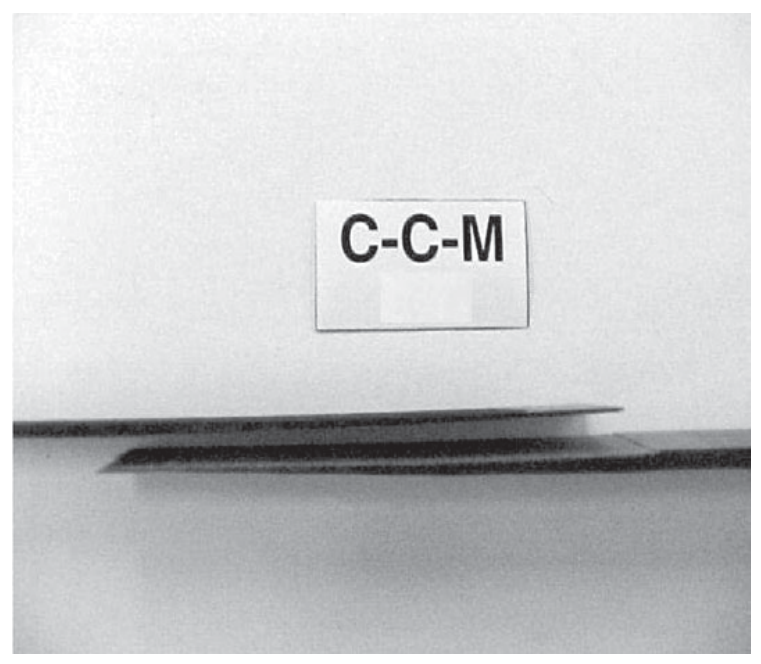

Figura 7. Falha típica dos laminados base com reparo, sob condicionamento úmido, com sobreposição de $9,0 \mathrm{~mm}$. Falha no adesivo.

propriedade de tração dos laminados sem reparo. Contudo, os laminados com reparo apresentaram uma redução significativa dessa propriedade, que é agravada com o ensaio nas condições úmida ambiente e úmida elevada, que provavelmente promove a degradação da interface e/ou o abaixamento da temperatura de transição vítrea do adesivo, prejudicando, conseqüientemente, a resistência da região de colagem. A sobreposição mais adequada para a execução de reparo submetido aos condicionamentos seco e úmido, a temperatura ambiente, é a de 15,0 mm, com o local de falha ocorrendo sempre no reparo ou no laminado base, como uma fratura translaminar. Esta sobreposição é escolhida como a mais adequada pelo fato de apresentar resistência à tração e desvio das medidas próximos aos obtidos para a sobreposição com 20,0 mm, porém com uma menor extensão e massa, atendendo com isso aos requisitos de balanço e de redução de massa da estrutura reparada. A falha de adesão, na sobreposição de 9,0 mm, mostra que este valor é inadequado para a execução de reparos.

A resistência dos laminados estudados foi restaurada parcialmente, variando-se o tamanho das sobreposições do material de reparo (máximo valor de recomposição foi de $84 \%$ ). Observou-se, também, que os corpos-de-prova reparados são muito susceptíveis ao ensaio na condição úmida elevada, indicando que o adesivo utilizado sofre degradação e/ou o decréscimo da sua temperatura de transição vítrea $\left(\mathrm{T}_{\mathrm{g}}\right)$ ou da $\mathrm{T}_{\mathrm{g}}$ do material do reparo, empobrecendo a interface entre os componentes. Portanto, novos filmes adesivos e materiais de reparo, mais resistentes à umidade, devem ser avaliados para a execução de reparos em laminados base de carbono/epóxi com tecido de carbono/epóxi.

\section{Agradecimentos}

Os autores agradem à EMBRAER e à Divisão de Materiais do Instituto de Aeronáutica Espaço/CTA pelo apoio recebido.

\section{Referências Bibliográficas}

1. Yosomiya, R.W. et al. "Adhesion and Bonding in Composites", Ed. Marcel Dekker, Inc., New York, 1990.

2. Ahn, S.H.; Springer G.S. Journal of Composite Material, 32 (11), p. 1036-1113, 1998.

3. Cândido, G.M. "Influência do condicionamento ambiental na resistência à delaminação de borda livre em compósitos avançados", Tese de doutorado, Instituto Tecnológico de Aeronáutica, Brasil, 2001.

4. Cândido, G.M.; Almeida, S.F.M.; Rezende, M.C. Polímeros: Ciência e Tecnologia, 10 (1), p. 31-41, 2000.

5. Silva, R.A. "Erosão em compósitos poliméricos", Dissertação de Mestrado, Instituto Tecnológico de Aeronáutica, Brasil, 2000.

6. Silva, R.A.; Rezende, M.C. Polímeros: Ciência e Tecnologia, 13(1), p. 79-86, 2003. 
7. Kaeble, D.H.; Dynes, P.J.; Cirlin, E.H. Journal Adhesion, 6, p. 23-30, 1974.

8. Derk, H. "Introduction to Composite Materials", Ed. Cambridge University Press, Cambridge, 1993.

9. Abaris Training - "Advanced Composite Structures: Fabrication and Damage Repair", Reno NV, EUA, 1998.

10. Niu, M.C.Y. "Composite airframe structures practical design information and data", Ed. Granada Hills, $3^{\text {nd }}$ ed, CA, 2000.

11. HEXCEL COMPOSITES - Resin systems for advanced composites. Pleasanton, CA: Hexcel Composites, 6 p., 1996.

12. HEXCEL COMPOSITES - Prepreg Technology. Pleasanton, CA: Hexcel Composites, 32 p., 1997.

13. Wittman, C.; Shook, G.D. Hand lay-up Techniques. Handbook of Composites, cap. 13, Lubin G. (ed), Van Nostrand Reinhold Company, New York, 1982.

14. Cândido, G.M.; Almeida, S.F.M.; Rezende, M.C. Efeitos do condicionamento higrotérmico e da seqüência de empilhamento das camadas em compósitos de carbono/epóxi com bordas moldadas. In: CD dos Anais do CONEM 2000 (Congresso Nacional de Engenharia Mecânica, 2000), Natal-RN,2000.

15. Cândido, G.M.; Rezende, M.C.; Almeida, S.F.M. Influência do efeito higrotérmico na resistência de laminados cruzados de carbono/epóxi com bordas moldadas In: CD dos Anais do 13ํㅡㄹ Congresso Brasileiro de Engenharia e Ciência dos Materiais, 13ํㅡㄹ CuritibaPR, 1998.

16. Standard Test Method for Tensile Properties of Polymer Matrix Composite. ASTM D3039/D 3039M-00, 2002.

17. MIL-HDBK-17-3F - Composite Materials Handbook. Polymer Matrix Composites Materials Usage, Design and Analysis, v. 3, 2002.

18. Matthews, F.L.; Rawling, R.D. Composite Material Engineering and Science, cap. 14, Chapman \& Hall, London, 1996.

Recebido: 08/11/2002

Aprovado: 10/04/2003 